Open Access

\title{
Diacerein retards cell growth of chondrosarcoma cells at the G2/M cell cycle checkpoint via cyclin B1/CDK1 and CDK2 downregulation
}

Birgit Lohberger ${ }^{1 *}$, Andreas Leithner ${ }^{1}$, Nicole Stuendl ${ }^{1}$, Heike Kaltenegger $^{1}$, Werner Kullich ${ }^{2}$ and Bibiane Steinecker-Frohnwieser ${ }^{2}$

\begin{abstract}
Background: Chondrosarcoma is characterized for its lack of response to conventional cytotoxic chemotherapy, propensity for developing lung metastases, and low rates of survival. Research within the field of development and expansion of new treatment options for unresectable or metastatic diseases is of particular priority. Diacerein, a symptomatic slow acting drug in osteoarthritis (SYSADOA), implicates a therapeutic benefit for the treatment of chondrosarcoma by an antitumor activity.

Methods: After treatment with diacerein the growth behaviour of the cells was analyzed with the xCELLigence system and MTS assay. Cell cycle was examined using flow cytometric analysis, RT-PCR, and western blot analysis of specific checkpoint regulators. The status for phosophorylation of mitogen-activated protein kinases (MAPKs) was analyzed with a proteome profiler assay. In addition, the possible impact of diacerein on apoptosis was investigated using cleaved caspase 3 and Annexin V/PI flow cytometric analysis.

Results: Diacerein decreased the cell viability and the cell proliferation in two different chondrosarcoma cell lines in a dose dependent manner. Flow cytometric analysis showed a classical G2/M arrest. mRNA and protein analysis revealed that diacerein induced a down-regulation of the cyclin B1-CDK1 complex and a reduction in CDK2 expression. Furthermore, diacerein treatment increased the phosphorylation of p38a and p38ß MAPKs, and Akt1, Akt2, and Akt 3 in SW-1353, whereas in Cal-78 the opposite effect has been demonstrated. These observations accordingly to our cell cycle flow cytometric analysis and protein expression data may explain the G2/M phase arrest. In addition, no apoptotic induction after diacerein treatment, neither in the Cal-78 nor in the SW-1353 cell line was observed.
\end{abstract}

Conclusions: Our results demonstrate for the first time that the SYSADOA diacerein decreased the viability of human chondrosarcoma cells and induces G2/M cell cycle arrest by CDK1/cyclin B1 down-regulation.

Keywords: Chondrosarcoma, Diacerein, Cell cycle arrest, Cyclin B1, CDK

\footnotetext{
*Correspondence: birgit.lohberger@medunigraz.at

'Department of Orthopedic Surgery, Medical University Graz,

Auenbruggerplatz 5, A-8036 Graz, Austria

Full list of author information is available at the end of the article
} 


\section{Background}

Diacerein represents a symptomatic slow acting drug in osteoarthritis (SYSADOA) from the anthraquinone chemical class and as the general term implicates, efficacy against the symptoms of osteoarthritis (OA) has been demonstrated [1]. As an anti-rheumatic drug, the potential of diacerein lies in the in vitro inhibition of the synthesis of interleukin-1 and its activity within the synthesis of proteoglycans, glycosaminoclycans, and hyaluronuic acid, principle components of cartilage extracellular matrix [2]. By using an experimental canine model of OA, an effective reduction in chondrocyte DNA fragmentation and cell death, due to a diacerein induced reduction of caspase-3 activity has been observed [3]. Within the early lesions of experimental OA the activation of the caspase cascade has been connected to chondrocyte death, whereas caspase as well as MEK1/2 and p38MAPK inhibitors reveal a marked deterioration of the programmed cell death and attenuate the severity of cartilage lesions $[4,5]$. Studying the cell proliferation and cell viability characteristics of C28/I2 chondrocytes, strikingly increased concentrations of diacerein significantly decreases cell growth and viability [6]. These observed growth-inhibiting qualities of diacerein, when applied at higher concentrations, might implicate a therapeutic benefit for the treatment of chondrosarcoma [7]. While diacerein has proved to be effective in the treatment of OA, Qin et al described that a diacerein $\alpha$-aminophosphonate conjugate has anti-proliferative activities on tumor cells [8].

Chondrosarcomas constitute a heterogeneous group of neoplasms, tumor cells with the common characteristics in terms of the production of components of the extracellular matrix within the cartilage [9]. With an incidence of 1:50,000, chondrosarcoma typically occurs in adults in their $3^{\text {rd }}$ to $6^{\text {th }}$ decade of life and represent the second most common primary malignant bone tumor in large epidemiologic series [10]. Wide surgical excision remains the best available treatment for intermediate- to high-grade tumors since they are relatively chemo- and radiotherapy resistant because of their extracellular matrix, low percentage of dividing cells, and poor vascularity, [11-14]. However, for high-grade chondrosarcoma, the prognosis is poor even after adequate surgery [15]. From the clinical point of view it is a huge challenge within the field of cancer treatment, to prevent recurrence and to find better treatment options for unresectable or metastatic diseases, such as chondrosarcoma.

The aim of this study was to show if diacerein is able to generate a reduction in cell growth and if this decline is generated by cell cycle arrest or apoptosis. Therefore, the effect of diacerein on cell proliferation, cell cycle distribution, and apoptosis of two human chondrosarcoma cell lines was investigated.

\section{Methods}

\section{Cell culture}

Human chondrosarcoma cell lines SW-1353 (CLS, Eppelheim, Germany) and Cal-78 (DSMZ, Braunschweig, Germany) were cultured in Dulbecco's-modified Eagle's medium (DMEM-F12; GIBCO ${ }^{\circ}$, Invitrogen, Darmstadt, Germany), containing $5 \%$ fetal bovine serum (FBS), 1 \% Lglutamine, 100 units $/ \mathrm{ml}$ Penicillin, $100 \mu \mathrm{g} / \mathrm{ml}$ Streptomycin, and $0.25 \mu \mathrm{g}$ Amphotericin B (all $\mathrm{GIBCO}^{\circ}$, Invitrogen). Both cell lines were verified by short tandem repeat analysis using PowerPlex 16 System Kit (Promega, Mannheim, Germany). Cells were kept at $37{ }^{\circ} \mathrm{C}$ in a humidified atmosphere of $5 \% \mathrm{CO}_{2}$ and were passaged by trypsinization after reaching 80-90\% confluence.

\section{Sample preparation}

Pure Diacerein (TRB Chemedica International, Geneva, Switzerland) was dissolved in DMSO and diluted with culture medium. The final DMSO concentration was max. $0.5 \%$, which did not affect the behavior of the cells as observed by benchmark experiments.

\section{Cell proliferation}

MTS assay (Brand, Voerde-Friedrichsfeld, Germany) was used to measure the metabolic activity of cells: $5 \times 10^{3}$ cells per well were seeded into 96 well plates and treated with $0-500 \mu \mathrm{M}$ diacerein. The cells were treated for $24 \mathrm{~h}$ and $48 \mathrm{~h}$, thereafter a CellTiter 96 AQueous Assay (Promega, Mannheim, Germany) was performed following the manufacturers' instructions; untreated cells were used for control (ctrl).

The $x$ CELLigence DP device from Roche Diagnostics (Mannheim, Germany) was used to monitor cell proliferation in realtime after cells were seeded on electronic microtiter plates (E-Plate; Roche Diagnostic) [16]. Cells were treated with $0,30,100$, and $300 \mu \mathrm{M}$ diacerein and the proliferation rate was measured for $24 \mathrm{~h}$. Cell index (CI) measurements were performed in triplicates with a signal detection set for every $20 \mathrm{~min}$. The cell index (CI) is a measure for the cell density of cells and was normalized to the time point when diacerein was added. Subsequent to the continuous xCELLigence cell monitoring, the slope $(1 / \mathrm{h})$ representing the rate of change of the cell index was calculated from time 7-24 h. Acquisition and analysis was performed with the RTCA software (Version 1.2, Roche Diagnostics).

\section{Flow cytometry for cell cycle analysis}

SW1353 and Cal-78 cells were treated with 30, 100, and $300 \mu \mathrm{M}$ diacerein. After a treatment time of 24 and $48 \mathrm{~h}$, respectively, the cells were harvested by trypsinization and fixed with $70 \%$ ice-cold ethanol for $10 \mathrm{~min}$ at $4{ }^{\circ} \mathrm{C}$. Next to washing, the cell pellet was re-suspended in PI-staining buffer $(50 \mu \mathrm{l} / \mathrm{ml}$ PI, RNAse A, Beckman 
Coulter, Brea, CA) and was incubated for $15 \mathrm{~min}$ at $37^{\circ} \mathrm{C}$. Cell cycle distribution was analyzed by FACS Calibur (BD Biosciences, San Diego, CA) using ModFit software.

\section{Reverse transcription polymerase chain reaction (RT-PCR)}

Total ribonucleic acid (RNA) was isolated from treated and untreated cells with the RNeasy Mini Kit and DNase-I treatment according to the manufacturer's manual (Qiagen, Hilden, Germany). One microgram RNA was reverse transcribed using a RevertAid cDNA Synthesis Kit (Fermentas). Amplification was achieved with the Platinum SYBR Green Super Mix with ROX (Invitrogen) on AB7900HT (Applied Biosystems, Invitrogen). Each qPCR run consisted of a standard 3-step PCR temperature protocol (annealing temperature of $60{ }^{\circ} \mathrm{C}$ ) followed by a melting curve protocol to confirm a single gene-specific peak and to detect primer dimerization. Relative quantification of expression levels were obtained by the $\Delta \Delta \mathrm{Ct}$ method based on the geometric mean of the internal controls glyceraldehyde 3-phosphate dehydrogenase (GAPDH), $\beta$-actin (ACTB), and hypoxanthine phosphoribosyltransferase (HPRT-1), respectively. The following primers were used for real time RT-PCR: QuantiTect primer assays (Qiagen) for cyclin B1 (ID QT00006615), CDK1 (ID QT00042672), and CDK2 (ID QT00005586). The expression level $\left(\mathrm{C}_{\mathrm{T}}\right)$ of the target gene was normalized to the reference genes $\left(\Delta C_{t}\right)$, the $\Delta C_{t}$ of the test sample was normalized to the $\Delta \mathrm{C}_{\mathrm{t}}$ of the control $\left(\Delta \Delta \mathrm{C}_{\mathrm{t}}\right)$. Finally, the expression ratio was calculated with the $2^{-\Delta \Delta \mathrm{Ct}}$ method $\left({ }^{*} p<0.05\right)$.

\section{Western blot analysis}

For immunoblotting, whole cell protein extracts were prepared with lysis buffer $(50 \mathrm{mM}$ Tris $-\mathrm{HCl} \mathrm{pH} 7.4$, $150 \mathrm{mM} \mathrm{NaCl}, 50 \mathrm{mM} \mathrm{NaF}, 1 \mathrm{mM}$ EDTA, 10 \% NP-40, $1 \%$ Triton-X, and protease inhibitors), subjected to SDS-PAGE (10 or $12 \%$ ) and blotted onto PVDF membrane (Roth, Karlsruhe, Germany). Primary antibodies against cyclin B1 (sc-245), CDK1 (sc-54), CDK2 (sc6248), and p53 (sc-126) were purchased from Santa Cruz (Santa Cruz Biotechnology, Santa Cruz, CA), phosphoHistone H2A.X (\#9718), Akt (\#9272), phospho-Akt (Ser473) (\#9271), p38 MAPK (\#9212), and phospho-p38 MAPK (Thr180/Tyr182) (\#4511) antibodies from Cell Signaling Technology (Cell Signaling Technology, Danvers, MA) and $\beta$-actin (A4700) from Sigma-Aldrich (Vienna, Austria). Blots were developed using horseradish peroxidase-conjugated secondary antibodies (Dako, Jena, Germany) at room temperature for $1 \mathrm{~h}$ and the SuperSignal $^{\circ}$ West Pico Chemoluminescent Substrate (Thermo Scientific, Rockford, IL), in accordance with the manufacturers' protocol.

\section{MAPK array}

For the Proteome Profiler Human Phospho-MAPK Array Kit (ARY002B; R\&D Systems, Minneapolis; MN), cells were treated with $30 \mu \mathrm{M}$ diacerein for $24 \mathrm{~h}$ and whole cell protein extracts were prepared with lysis buffer. Capture and control antibodies of the major families of mitogenactivated protein kinases (MAPKs), the extracellular signalregulated kinases (ERK1/2), c-Jun $\mathrm{N}$-terminal kinases (JNK1-3), and different $\mathrm{p} 38$ isoforms $(\alpha / \beta / \delta / \gamma)$, have been spotted in duplicate on nitrocellulose membranes. To analyzing the phosphorylation status the array was performed following the manufacturers' instructions; untreated cells were used for control.

\section{Caspase-3 apoptosis assay}

After incubation with with 30,100 , and $300 \mu \mathrm{M}$ diacerein for $48 \mathrm{~h}$, cells were harvested by trypsinization, fixed with formaldehyde for $10 \mathrm{~min}$ at $37^{\circ} \mathrm{C}\left(2 \times 10^{6} \mathrm{cells} / \mathrm{ml}\right)$, permeabilized with methanol, and finally re-suspended in incubation-buffer (FBS:PBS 1:200). Caspase-3, a marker for cells that undergo apoptosis, is activated by the proteolytic processing of its inactive zymogen into the activated p17 and p12 fragments, respectively. The FITC-conjugated monoclonal cleaved caspase-3 (Asp175) antibody (\#9661; Cell Signaling Technology) detects endogenous levels of the large fragment $(17 / 19 \mathrm{kDa})$, released after the activation of caspase-3. The antibody does not recognize full length caspase- 3 or other cleaved caspases. Cells were analyzed by flow cytometry (FACS Calibur, BD Biosciences) performed with FACSDiva software. Histograms were created using FCS3 express software (De Novo software, Los Angeles, CA). Untreated cells were used as negative control.

\section{Annexin V/PI apoptosis assay}

The APC Annexin V Apoptosis Detection Kit (BioLegends, San Diego, CA) was performed following the manufacturers' instructions. Apoptotic cells were identified by the incubation of $1 \times 10^{5}$ cells in $100 \mu \mathrm{l}$ Annexin V binding buffer containing $5 \mu \mathrm{l}$ Annexin V-APC and $5 \mu \mathrm{l}$ PI for $15 \mathrm{~min}$ at room temperature. Flow cytometry analysis was performed with FACS Calibur (BD Biosciences); 10,000 events were collected. Cells were identified in the side scatter and forward scatter with linear scale. Fluorescence signals were shown with logarithmic scale. Compensation was performed by single Annexin and PI measurements and analyzed by FCS3 express software (De Novo software). Untreated cells were used as negative control.

\section{Statistical analysis}

All values are expressed as mean values \pm SD. Student's unpaired $t$-test was used to evaluate differences between treated groups and their respective controls. The significance of dose or time responses was assessed by repeated 
measures analysis. Graphic data were prepared and calculated with SigmaPlot ${ }^{\circ}$ (Systat Software Inc., San Jose, CA).

\section{Results}

Diacerein reduced cell proliferation and viability of chondrosarcoma cells

Chondrosarcoma cells were treated with 30, 100, and $300 \mu \mathrm{M}$ diacerein for $48 \mathrm{~h}$. During this period, cell growth curves were automatically recorded in real time by the xCELLigence System (Fig. 1a). Diacerein inhibited cell growth in a concentration dependent manner in both cell lines. While an effect on Cal-78 cells could only be observed at a concentration of $300 \mu \mathrm{M}$ diacerein, causing a complete reduction of cell proliferation, SW-1353 cells demonstrated a higher sensitivity for diacerein illustrated by a considerably reduced cell index at a concentration of 30 and $100 \mu \mathrm{M}$. A block of cell growth or rather an induced cell death may contribute to this decrease in cell index. In Cal-78 cells slope values changed under the influence of diacerein from $0.022 \pm$ 0.007 (ctrl) to $0.025 \pm 0.006(30 \mu \mathrm{M}),-0.007 \pm 0.016$ $(100 \mu \mathrm{M} ; p=0.001)$, and $-0.035 \pm 0.007(300 \mu \mathrm{M} ; \mathrm{p}=$ 8.77E-11). In SW-1353 cells a change from $0.144 \pm 0.026$ (ctrl) to $0.166 \pm 0.082(30 \mu \mathrm{M}), 0.028 \pm 0.055(100 \mu \mathrm{M}$; $p=0.012)$, and $-0.028 \pm 0.013(300 \mu \mathrm{M} ; p=1.01 \mathrm{E}-10)$ could be observed.

To investigate the influence on cell viability, chondrosarcoma cell lines were exposed to $0,3,10,30,100$, and $300 \mu \mathrm{M}$ of diacerein for 24 and $48 \mathrm{~h}$. After the equivalent treatment, cells were measured by the MTS assay

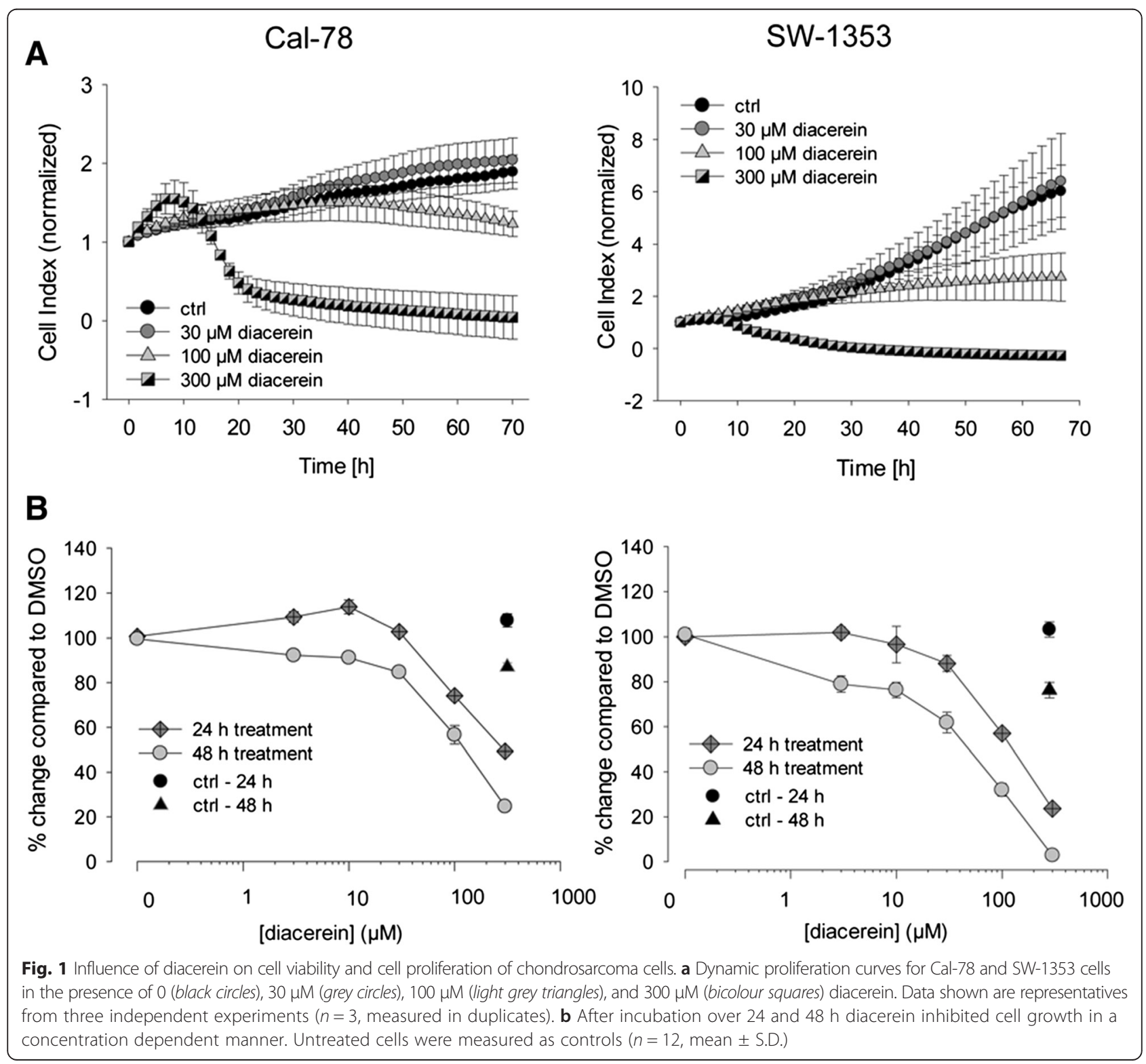


$(n=12)$. Figure $1 \mathrm{~b}$ shows the time- and dose-dependent inhibition of cell viability.

\section{Diacerine caused a cell cycle G2/M arrest}

To investigate the effects of diacerein on cell cycle, chondrosarcoma cells were exposed to 30, 100, and $300 \mu \mathrm{M}$ diacerein. Untreated cells were measured as controls. The cell cycle distribution for both cell lines (Cal-78 and SW-1353) is summarized in form of the stacked bar chart given in Fig. 2a. In SW-1353 cells, diacerein caused after $48 \mathrm{~h}$ exposure a pronounced decrease in the number of cells in the G1 (grey bars) phase, accompanied by a significant increase of the number of S (black bars) and G2/M phase (striated bars) cells, indicating a $\mathrm{G} 2 / \mathrm{M}$ arrest. In the Cal-78 cell line only a moderate tendency towards G2/M phase could be observed. Representative measurements of untreated (control) and diacerein treated SW-1353 cells are depicted to highlight the differences (Fig. 2b). All values of three individual experiments (\% of gated cells) are listed in Table 1.

\section{Diacerein decreased cyclin B1, CDK1, and CDK2 levels}

Relative mRNA expression levels of cyclin B1, CDK1, and CDK2 were analyzed by real time RT-PCR after treatment of 30 and $100 \mu \mathrm{M}$ diacerein for $48 \mathrm{~h}$ (Fig. 3a). Untreated control cells served as reference value $($ ratio $=1)$. In the case of Cal-78 cells treatment with diacerein $(100 \mu \mathrm{M})$ induced a small, but not significant change, for the expression of CDK1, whereas the cyclin B1 and CDK2 levels were significantly down-regulated (cyclin B1: $0.612 \pm 0.22$ $(p=0.039)$; $\mathrm{CDK} 2: 0.673 \pm 0.16(p=0.027))$ within the

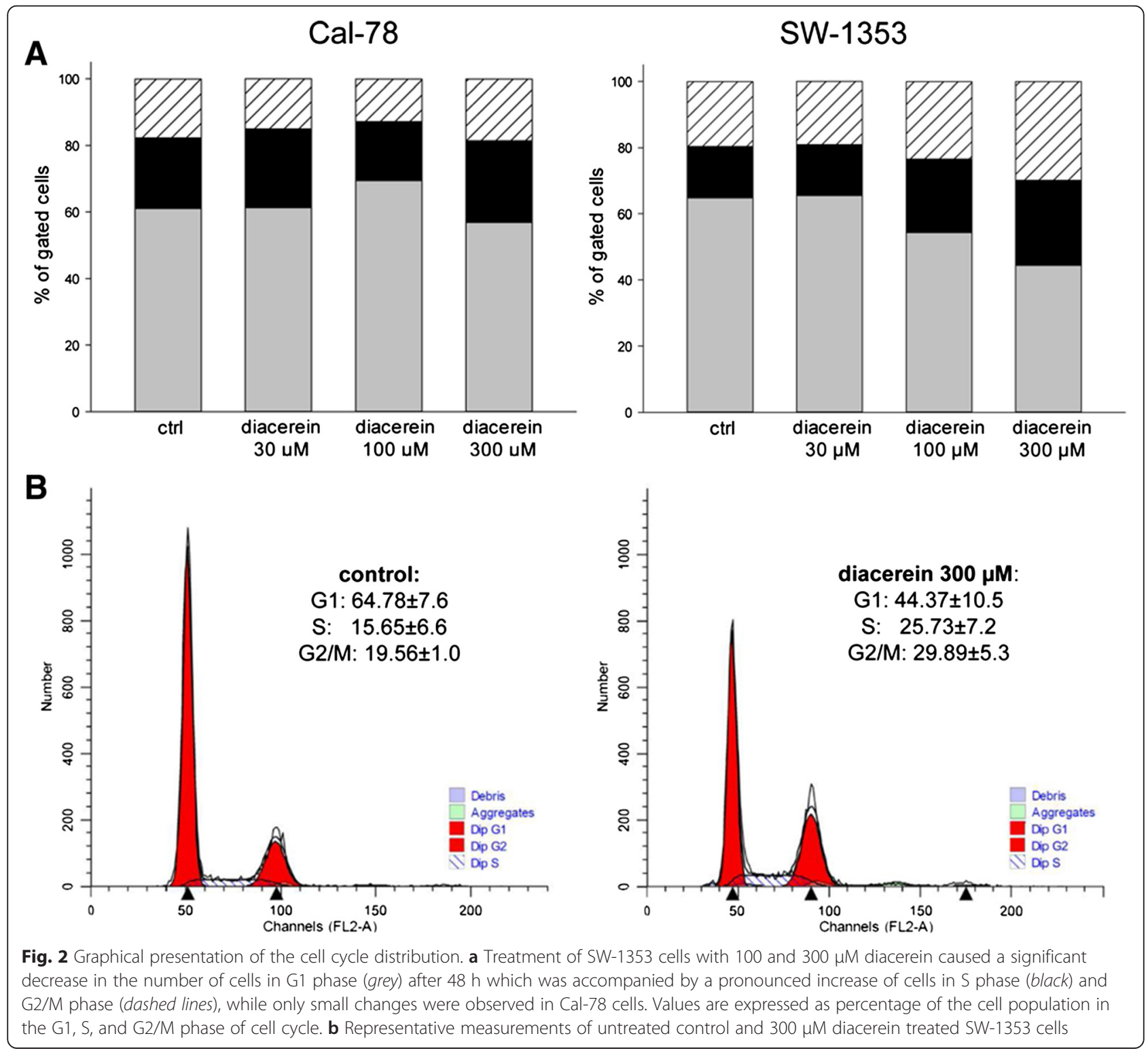


Table 1 Cell cycle distribution of chondrosarcoma cell lines after 24 and 48 h exposure to different concentrations of diacerein ${ }^{a}$

\begin{tabular}{|c|c|c|c|c|c|}
\hline Cell line & Treatment & $\mathrm{h}$ & G0/G1 (\%) & $\mathrm{S}(\%)$ & G2/M (\%) \\
\hline \multirow[t]{8}{*}{ Cal-78 } & control & $24 \mathrm{~h}$ & $57.48 \pm 8.19$ & $23.79 \pm 5.84$ & $18.73 \pm 2.51$ \\
\hline & diacerein $30 \mu \mathrm{M}$ & $24 \mathrm{~h}$ & $57.57 \pm 8.30$ & $25.23 \pm 4.69$ & $17.22 \pm 3.68$ \\
\hline & diacerein $100 \mu \mathrm{M}$ & $24 \mathrm{~h}$ & $62.04 \pm 5.54$ & $22.01 \pm 2.64$ & $15.94 \pm 2.85$ \\
\hline & diacerein $300 \mu \mathrm{M}$ & $24 \mathrm{~h}$ & $54.15 \pm 7.33$ & $26.76 \pm 8.21$ & $19.08 \pm 3.67$ \\
\hline & control & $48 \mathrm{~h}$ & $61.08 \pm 3.03$ & $21.23 \pm 2.31$ & $17.68 \pm 0.89$ \\
\hline & diacerein $30 \mu \mathrm{M}$ & $48 \mathrm{~h}$ & $61.31 \pm 1.16$ & $23.66 \pm 2.55$ & $15.03 \pm 1.80$ \\
\hline & diacerein $100 \mu \mathrm{M}$ & $48 \mathrm{~h}$ & $69.42 \pm 2.80^{*}$ & $17.79 \pm 2.38$ & $12.78 \pm 3.92$ \\
\hline & diacerein $300 \mu \mathrm{M}$ & $48 \mathrm{~h}$ & $56.95 \pm 12.37$ & $24.51 \pm 9.02$ & $18.53 \pm 4.09$ \\
\hline \multirow[t]{8}{*}{ SW-1353 } & control & $24 \mathrm{~h}$ & $51.14 \pm 7.05$ & $22.73 \pm 6.01$ & $26.12 \pm 1.35$ \\
\hline & diacerein $30 \mu \mathrm{M}$ & $24 \mathrm{~h}$ & $49.05 \pm 5.46$ & $27.15 \pm 6.08$ & $23.79 \pm 1.23$ \\
\hline & diacerein $100 \mu \mathrm{M}$ & $24 \mathrm{~h}$ & $55.95 \pm 4.11$ & $19.53 \pm 6.81$ & $24.52 \pm 6.83$ \\
\hline & diacerein $300 \mu \mathrm{M}$ & $24 \mathrm{~h}$ & $45.32 \pm 12.41$ & $25.35 \pm 8.41$ & $29.33 \pm 7.06$ \\
\hline & control & $48 \mathrm{~h}$ & $64.77 \pm 7.67$ & $15.65 \pm 6.65$ & $19.56 \pm 1.03$ \\
\hline & diacerein $30 \mu \mathrm{M}$ & $48 \mathrm{~h}$ & $65.54 \pm 5.75$ & $15.37 \pm 5.80$ & $19.08 \pm 0.31$ \\
\hline & diacerein $100 \mu \mathrm{M}$ & $48 \mathrm{~h}$ & $54.36 \pm 5.92$ & $22.16 \pm 10.54$ & $23.47 \pm 4.86$ \\
\hline & diacerein $300 \mu \mathrm{M}$ & $48 \mathrm{~h}$ & $44.38 \pm 10.52^{*}$ & $25.73 \pm 7.23$ & $29.89 \pm 5.33^{*}$ \\
\hline
\end{tabular}

${ }^{a}$ Asterisks represent significant differences between control and treated cells $(p<0.0 .5 ; n=3$; mean \pm S.D. $)$

observation period. In SW-1353 cells a highly significant down-regulation by $100 \mu \mathrm{M}$ diacerein in the expression of cyclin B1 to $0.095 \pm 0.03(p=1.28 \mathrm{E}-05)$, CDK1 levels to $0.154 \pm 0.02(p=9.82 \mathrm{E}-06)$, and the CDK2 levels to $0.443 \pm$ $0.12(p=0.002)$ could be demonstrated.

In order to substantiate our observations, western blot analysis for the specific regulatory proteins responsible for the G2/M transition under the exposure of 30, 100, and $300 \mu \mathrm{M}$ diacerein for $48 \mathrm{~h}$ were performed (Fig. 3b). Corresponding to the real time RT-PCR data, the expression of cyclin B1 and its corresponding cyclin-dependent kinases CDK1 and CDK2 were clearly declined in diacerein treated SW-1353 cells, whereas diacerein affected the expression of these $\mathrm{G} 2 / \mathrm{M}$ checkpoint regulator proteins in Cal-78 cells only to a small extent. Figure 3c represents the quantitative evaluation of the western blot analysis of three independent experiments. All values were normalized to their corresponding $\beta$-actin.

\section{Phosphorylation of MAPKs under diacerein treatment}

Treatment with $30 \mu \mathrm{M}$ diacerein for $24 \mathrm{~h}$ increased the phosphorylation of $\mathrm{p} 38 \alpha$ (17.07 \% change) and $\mathrm{p} 38 \beta$ (34.01 \%) MAPKs in SW-1353 cells, whereas in Cal-78 the observed phosphorylation changed to the contrary

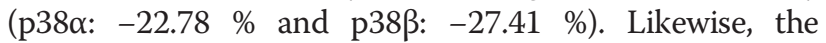
MKK3 and MKK6 phosphorylation increased considerably (MKK3: 28.19 \% and MKK6: 22.59 \%) in SW-1353 cells, and decreased in Cal-78 cells (MKK3: $-26.75 \%$ and MKK6: $-18.87 \%)$. The same picture is given for members of the Akt family: a down-regulation for the Cal-78 cells (Akt1: $-23.34 \%$, Akt2: $-16.70 \%$, and Akt3: $-20.13 \%$ ) and an augmentation when tested in SW1353 cells (Akt1: $12.85 \%$, Akt2: $19.29 \%$, and Akt3: $9.23 \%$ ) (Fig. 4a).

Western blot analysis confirmed the results from the proteome profiler phospho-MAPK array (Fig. 4b). Phosphorylation of Akt (pAkt) and p38 (pp38) were upregulated after the treatment with different concentrations of diacerein in SW-1353 cells, whereas, only minor changes can be observed in the Cal-78 cells. The used phosphoAkt antibody detects endogenous levels of Akt1, Akt2, and Akt3 only when phosphorylated at Ser473. The used p38 MAPK antibody detects endogenous levels of total $\mathrm{p} 38 \alpha,-\beta$ and $-\gamma$ MAPK protein. In addition, the expression of p53 was diminished in Cal-78 cells. The crosslinking of interesting genes of cell cycle regulation and MAPK pathways is given in Fig. 4c using IPA (Ingenuity Pathway Analysis) software.

\section{Diacerein did not induce apoptosis}

Apoptosis induction was investigated by flow cytometric analysis of caspase-3 cleavage (Fig. 5a) and Annexin V/PI staining (Fig. 5b). Figure 4a shows the cleaved caspase-3 measurements after a $48 \mathrm{~h}$ exposure of the cells to 30, 100 , and $300 \mu \mathrm{M}$ diacerein. The flow cytometric analysis histograms represent untreated cells (black filled) versus $30 \mu \mathrm{M}$ diacerein (striated lines), $100 \mu \mathrm{M}$ diacerein (blue lanes), and $300 \mu \mathrm{M}$ diacerein (margenta lanes) treated cells. Green lanes represent the Staurosporin positive control. In both cell lines only minimal caspase- 3 cleavage could be detected, worth mentioning is the minor dose response detectable for the curve shift to the right within Cal-78 cells. Although, induction of apoptosis was further 
A

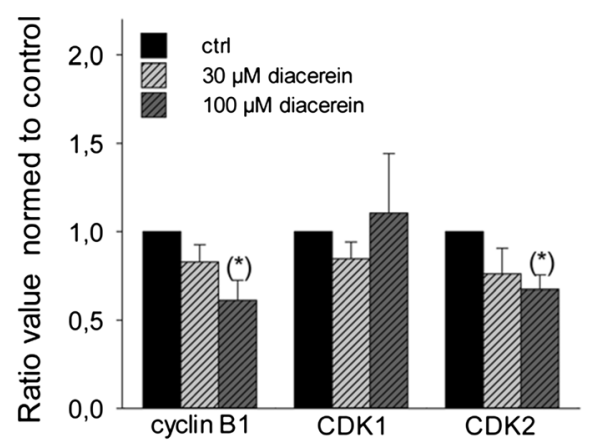

B

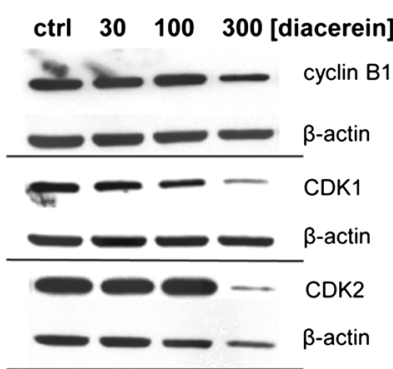

C

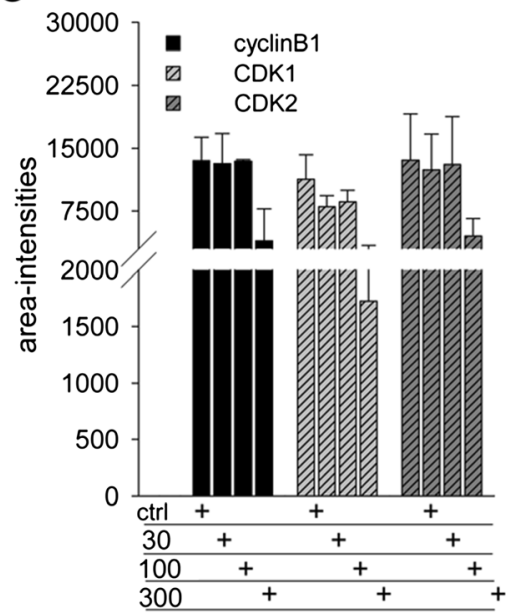

SW-1353

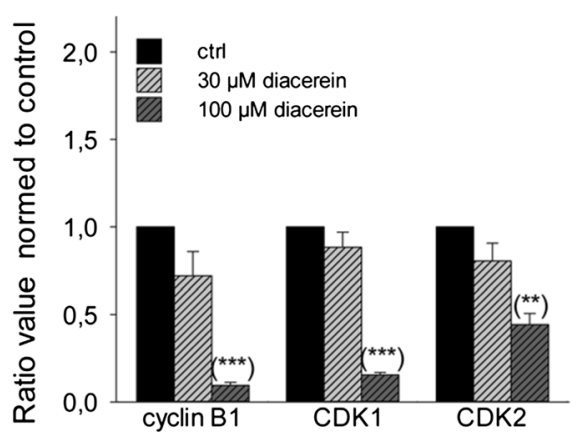

ctrl 30100300 [diacerein] $(\mu \mathrm{M})$
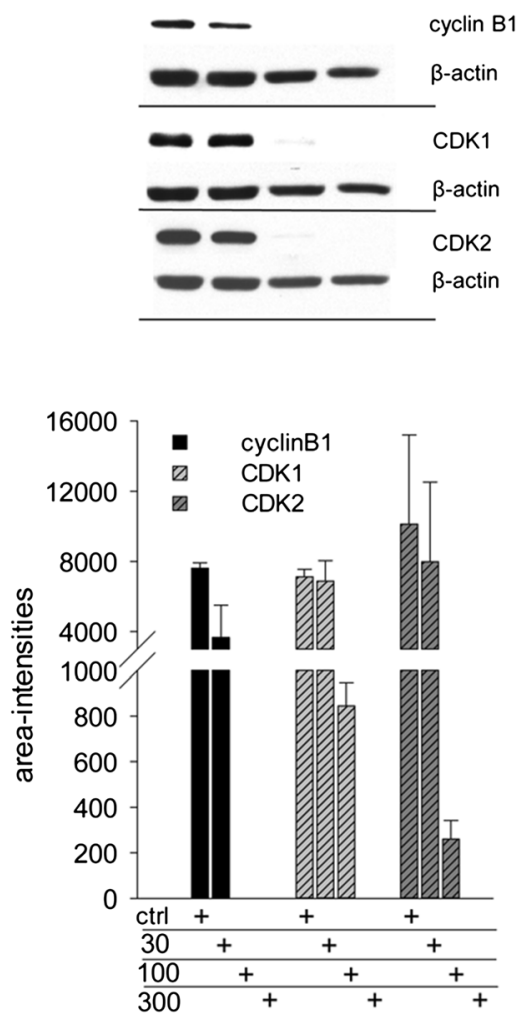

Fig. 3 Regulation of the cell cycle checkpoints. a Relative mRNA expression of the cell cycle regulators cyclin B1, CDK1, and CDK2 after $48 \mathrm{~h}$ incubation with 30 and $100 \mu \mathrm{M}$ diacerein. Asterisks represent significant differences between control and treated cells $\left({ }^{*} p<0.05 ;{ }^{* *} p<0.01 ;{ }^{* *}\right.$ $p<0.001)$. $\mathbf{b}$ Total protein analysis after $48 \mathrm{~h}$ of treatment revealed a significant down-regulation of the $\mathrm{G} 2 / \mathrm{M}$ arrest regulator proteins cyclin B1, CDK1, and CDK2 in 100 and $300 \mu \mathrm{M}$ diacerein treated chondrosarcoma cells. $\beta$-actin was used as loading control. c Quantitative evaluation of the western blot analysis of cell cycle regulator proteins

verified by Annexin V/PI staining, in accordance with the caspase-3 data, chondrosarcoma cells did not elicit an increase in Annexin positive cells. Studying the phosphoHistone H2A.X DNA damage marker, a slight concentration dependent increase in expression was detected for Cal-78 cells under the treatment with diacerein, while the SW-1353 cells did not show a response at the H2A.X expression level (Fig. 5c). These sets of data imply that diacerein do not significantly influence the induction of apoptosis.

\section{Discussion}

Chondrosarcoma is characterized for its lack of response to conventional cytotoxic chemotherapy, propensity for developing lung metastases, and poor survival. Therefore research within the field of development and expansion of new treatment options is of particular priority.

The applied concentration of $100 \mu \mathrm{M}$ diacerein reduced the cell viability of human chondrocytes by $20 \%$ and accordingly induced a decrease in cell growth, while these 


\section{A}

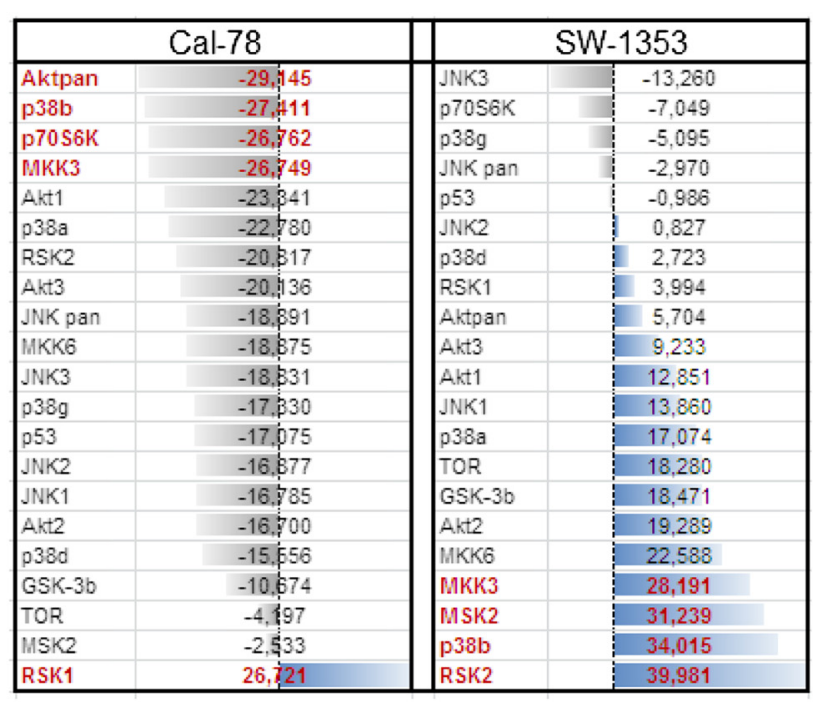

\section{B $\quad$ ctrl $\quad 30 \quad 100 \quad 300 \quad$ ctrl $30 \quad 100 \quad 300$ [diacerein] $(\mu M)$}
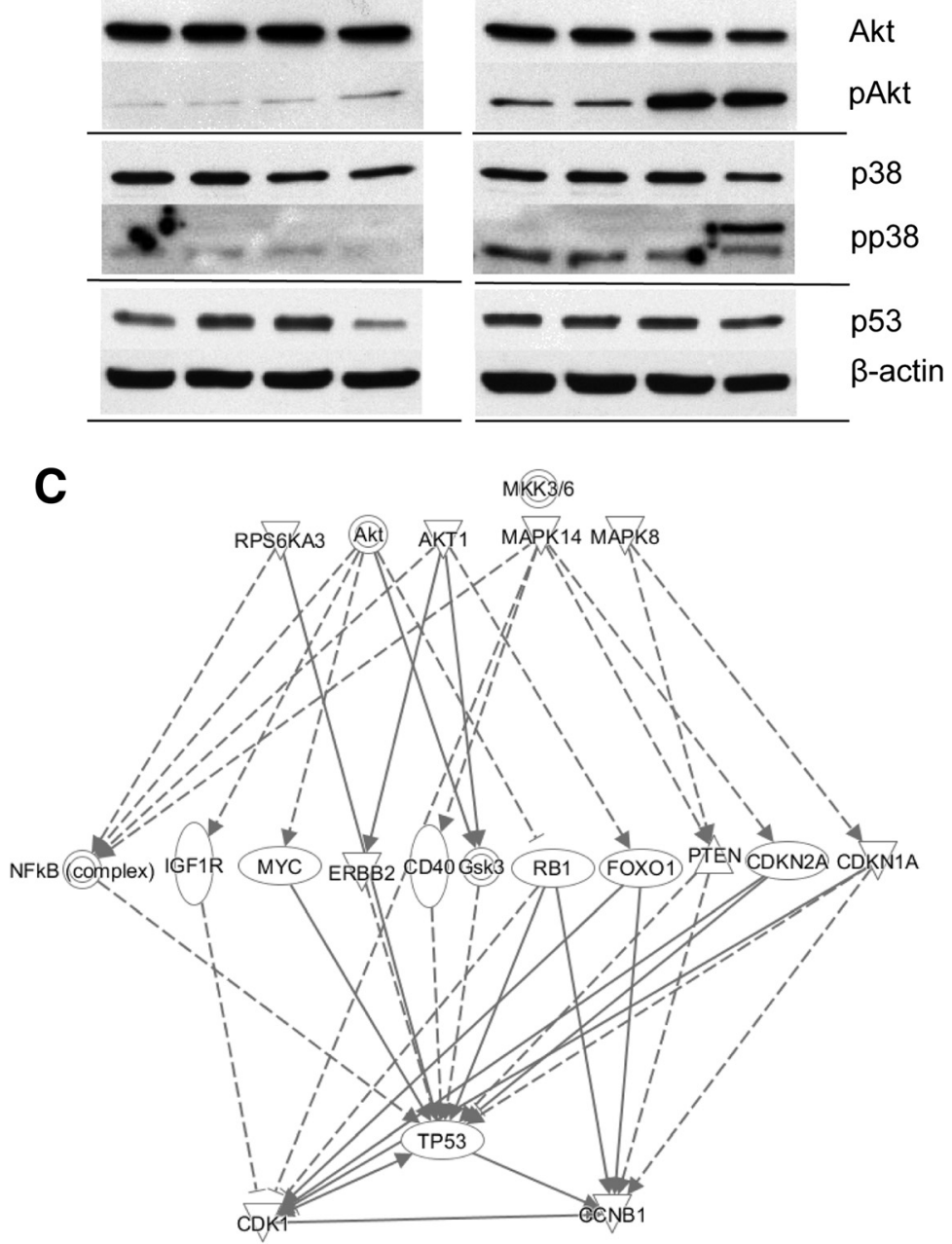

Fig. 4 (See legend on next page.) 
(See figure on previous page.)

Fig. 4 Phosphorylation of MAPKs under diacerein treatment. a MAPKs phosphorylation of Cal-78 and SW-1353 chondrosarcoma cell lines in percent change after $30 \mu \mathrm{M}$ diacerein for $24 \mathrm{~h}$. $\mathbf{b}$ Western blot analysis confirmed the results of the proteome profiler phospho-MAPK array and showed a significant increase of phospho-Akt and phospho-p38 after the treatment with different concentrations of diacerein in SW-1353 cells, whereas, no significant changes can be observed in the Cal-78 cells. The expression of p53 was diminished in Cal-78 cells. c Relationship of interesting genes using IPA (Ingenuity Pathway Analysis)

two observations point to the fact that diacerein modulates cellular physiology [6]. Rhein, the metabolite of diacerein, has been demonstrated to induce anti-catabolic and antiproliferative effects on chondrocytes stimulated by IL-1 $\beta$ at similar concentrations. Both effects were interpreted by alterations in cell cycle regulation and not by action of apoptosis [17]. However, the effect on chondrosarcoma has not been examined yet.

In initial experiments we showed, that in two different chondrosarcoma cell lines diacerein decreased the cell viability and the cell proliferation in a dose dependent manner. To identify the mechanism behind, within this study we reviewed the effect of diacerein on cell cycle distribution, the expression of cell cycle checkpoint proteins, the mitogen-activated protein kinases (MAPKs) pathways, and the induction of apoptosis in SW-1353 and Cal-78 cell lines.

In eukaryotes, the cell cycle is regulated by cyclins and cyclin-dependent kinases (CDKs). Cell cycle checkpoints enable cellular repair or may result in the activation of apoptosis signalling, if the cellular damages are significantly intense to be repaired properly $[18,19]$. In particular, cyclin $\mathrm{B}$ and $\mathrm{CDK} 1$ proteins participate in the regulation of the progression of $\mathrm{G} 2 / \mathrm{M}$ phase [20]. It is
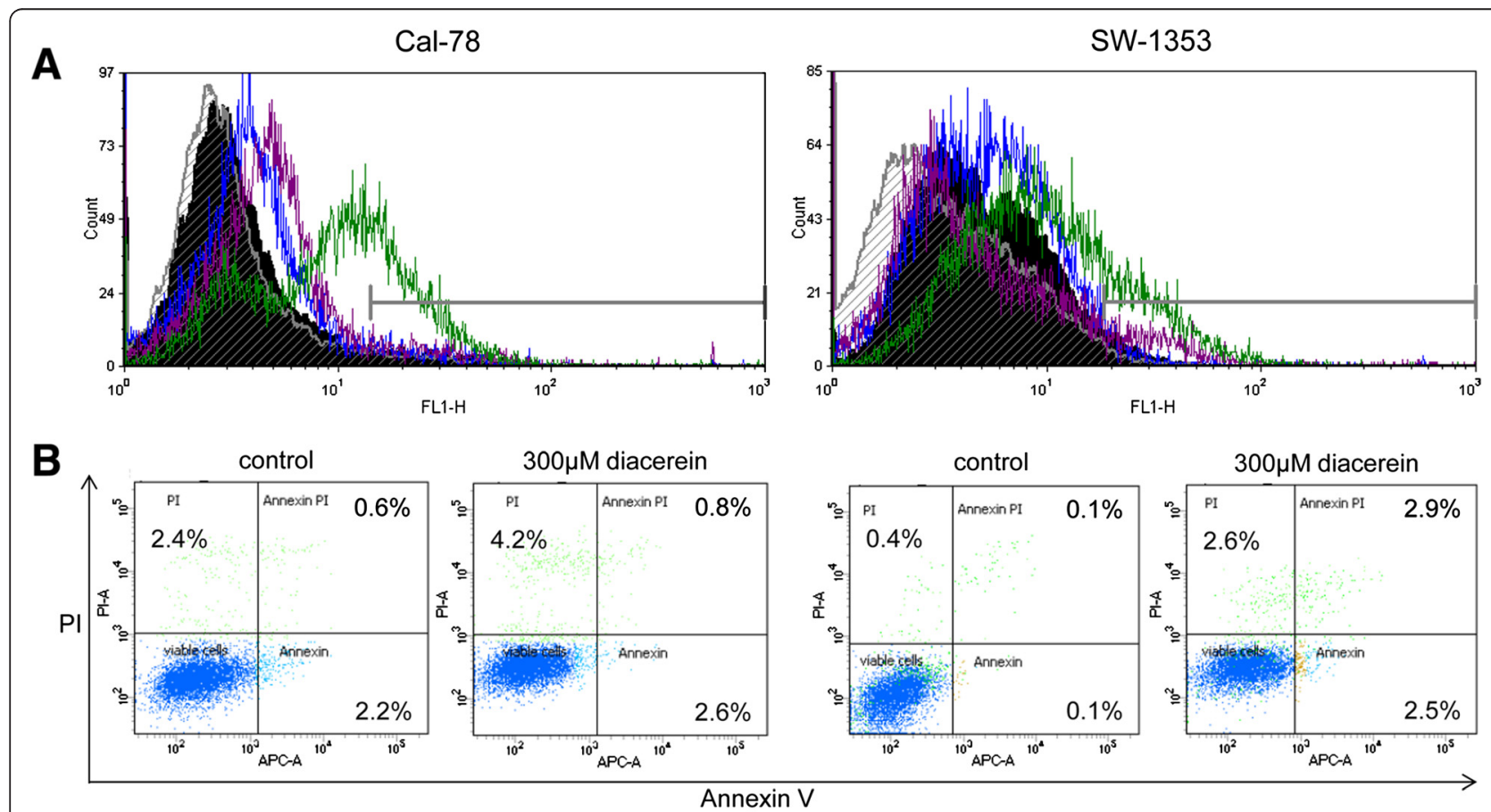

C

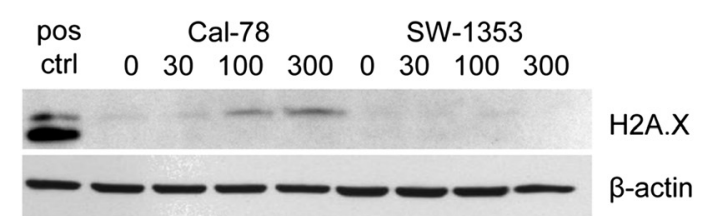

Fig. 5 Cleaved caspase-3 and Annexin V/PI apoptosis assays. a Cal-78 and SW-1353 cells were treated with $300 \mu$ M diacerein. Cleavage of caspase-3 was detected after $48 \mathrm{~h}$ by flow cytometry. The $y$-axis denotes cell counts and the $x$-axis represents fluorescence intensity of APC antibody. Black filled histogram represents untreated control cells, striated histogram represents $30 \mu \mathrm{M}$ diacerein, blue lanes showed $100 \mu \mathrm{M}$ diacerein, and margenta lanes showed $300 \mu \mathrm{M}$ diacerein treated cells. Green lanes represented the Staurosporin positive control. b Likewise, AnnexinV/PI staining under the influence of $300 \mu \mathrm{M}$ diacerein for $48 \mathrm{~h}$ confirmed the lack of apoptosis induction. c In Cal-78 cells, the DNA damage marker H2AX was marginally increased. $\beta$-actin was used as loading control 
widely known that cells are blocked in the G2/M phase during DNA damage, and cells are more susceptible to the cytotoxic effects of radiotherapy in the G2/M phase [21]. Increasing induced $G 2 / M$ phase arrest allows cell death which may be a useful strategy in cancer therapeutics [22].

The results of FACS analysis of SW-1353 cells treated with diverse concentrations of diacerein showed a decrease in the number of cells in G1 and S phase which was accompanied by a significant increase of the number of G2/M phase cells, strongly indicating a classical G2/ $\mathrm{M}$ arrest. Interestingly, in the Cal-78 cell line only small changes in cell cycle distribution could be detected, a fact possibly ascribed to the differences in the origin of the two cell lines. SW-1353 cells were obtained from a primary grade II chondrosarcoma of the right humerus, whereas the Cal-78 cells were established from the recurrence of a dedifferentiated chondrosarcoma (grade III) of the muscle.

We further explored the effect of diacerein on the key regulators in the cell cycle checkpoints including CDK1, CDK2, and cyclin B1 in Cal-78 and SW-1353 cells. The CDK1-cyclin B1 complex is pivotal in regulating the G2/ $M$ phase transition and mitosis. We observed a significant decrease in the mRNA and protein expression levels of cyclin B1 and CDK1 in SW-1353, whereas in Cal-78 cells only the protein expression of cyclin B1 was significantly affected. The diacerein induced downregulation of the cyclin B1-CDK1 complex might explain the observed reduction in cell growth in chondrosarcoma cells. Cyclin B1 is responsible for the transition of the cell from the $G 2$ to the $M$ phase but changes to a disruption in cancer cells where overexpression of cyclin B1 can lead to uncontrolled cell growth [19]. In addition both cell lines feature a significant reduction of CDK2 expression verified at the RNA and protein level, respectively. Altogether we are able to postulate, that diacerein influences cell cycle of chondrosarcoma cells, whereas the extent of the expression level of regulatory proteins involved appear to depend on the source of the cells. In our study Cal-78 cells are obvious more insensitive to diacerein regarding the cell cycle controls than the SW-1353 cells.

MAPKs are signaling components that are important in converting extracellular stimuli into a wide range of cellular responses. Signaling network is increasingly important for our comprehension of cell proliferation. The p38 MAPK as an important stress kinase is involved in the regulation of inflammation, cell growth and differentiation, cell cycle, and cell death [23]. Four isoforms of p38, known as p38 $\alpha, \mathrm{p} 38 \beta, \mathrm{p} 38 \gamma$, and $\mathrm{p} 38 \delta$ have been identified, which can all be phosphorylated by the MAPK kinase MKK6 (SKK3) and MKK3, respectively [24]. p38 can negatively regulate cell cycle progression both at the G1/S and the G2/M transitions by several mechanisms, including the down-regulation of cyclins, up-regulation of CDK inhibitors and modulation of the tumor suppressor p53 [25]. Moreover, we also provided evidence about the existence of a crosstalk between the p38 MAPK and Akt/mTOR signaling pathways in SW1353 cells exposed to diacerein. In the present study, we have observed that diacerein treatment significantly increases the phosphorylation of p38 $\alpha$ and p38 $\beta$ MAPKs in SW-1353, whereas Cal-78 shows a decrease of these p38-MAPKs. These observations are in accordance with our cell cycle FACS and protein expression data. The serine-threonine Akt kinase family is well-known as crucial regulators of cell survival, proliferation, metabolism, and migration [26]. Deregulation of Akt kinases is frequently associated with human diseases such as cancer [27]. It has been reported previously that Akt activity is high in the G2/M phase of the cell cycle in epithelial cells [28]. Akt activity protects cells from apoptosis during the G2/M transition and is necessary for efficient changeover to mitosis during unperturbed cell cycles [29]. In addition to its role in cell cycle progression, Aktmediated phosphorylation and cytoplasmic translocation of CDK2 is also important for apoptosis induced by stresses such as methotrexate and docetaxel [30]. Therefore, an increased phosphorylation of Akt1, Akt2, and Akt 3 in the SW-1353 cells after diacerein treatment explained the G2/M phase arrest.

These observed growth-inhibiting characteristics of higher concentrations of diacerein might implicate a therapeutic benefit for the treatment of chondrosarcoma. To elucidate the apoptotic potential of diacerein on chondrosarcoma cells, we have performed two different apoptosis assays. Diacerein treatment showed no apoptotic induction, neither in the Cal-78 nor in the SW-1353 cell line.

\section{Conclusion}

Our results demonstrate for the first time that diacerein decreased the viability of human chondrosarcoma cells and induces $\mathrm{G} 2 / \mathrm{M}$ cell cycle arrest by $\mathrm{CDK} 1 /$ cyclin $\mathrm{B} 1$ down-regulation. In summary, our findings strongly support diacerein as an interesting target for further investigation and development of novel therapeutics in sarcoma research.

\section{Abbreviations}

ACTB: $\beta$-actin; CDK: Cyclin-dependent kinase; Cl: Cell index; ERK1/2: Extracellular signal-regulated kinases 1/2; GAPDH: Glyceraldehyde 3-phosphate

dehydrogenase; HPRT-1: Hypoxanthine phosphoribosyl-transferase; JNK1-3: c-Jun N-terminal kinases 1-3; MAPKs: Mitogen-activated protein kinases; OA: Osteoarthritis; RNA: Ribonucleic acid; RT-PCR: Reverse transcription polymerase chain reaction; SYSADOA: Symptomatic slow acting drug in osteoarthritis.

\section{Competing interests}

The authors declare that they have no competing interests. 


\section{Authors' contributions}

$B L$ and BSF conceived and supervised the study. NS, HK, and BSF performed the experiments. BL and BSF analyzed and interpreted the data. BL, BSF, and $A L$ drafted and revised the manuscript. WK and AL provided technical support. All authors read and approved the final manuscript.

\section{Acknowledgement}

Financial support from the Medical University of Graz is gratefully acknowledged.

\section{Author details}

'Department of Orthopedic Surgery, Medical University Graz, Auenbruggerplatz 5, A-8036 Graz, Austria. ${ }^{2}$ Ludwig Boltzmann Institute for Rehabilitation of Internal Diseases, Ludwig Boltzmann Cluster for Rheumatology, Balneology and Rehabilitation, Saalfelden, Austria.

Received: 30 July 2015 Accepted: 6 November 2015 Published online: 10 November 2015

\section{References}

1. Bjornsson J, McLeod RA, Unni KK, Ilstrup DM, Pritchard DJ. Primary chondrosarcoma of long bones and limb girdles. Cancer. 1998:83(10):2105-19.

2. Cho HJ, Oh YJ, Han SH, Chung HJ, Kim CH, Lee NS, et al. Cdk1 proteinmediated phosphorylation of receptor-associated protein 80 (RAP80) serine 677 modulates DNA damage-induced G2/M checkpoint and cell survival. J Biol Chem. 2013;288(6):3768-76.

3. D'Adamo DR. Appraising the current role of chemotherapy for the treatment of sarcoma. Semin Oncol. 2011;38 Suppl 3:S19-29.

4. D'Lima D, Hermida J, Hashimoto S, Colwell C, Lotz M. Caspase inhibitors reduce severity of cartilage lesions in experimental osteoarthritis. Arthritis Rheum. 2006:54(6):1814-21.

5. Damron TA, Ward WG, Stewart A. Osteosarcoma, chondrosarcoma, and Ewing's sarcoma: National Cancer Data Base Report. Clin Orthop Relat Res. 2007:459:40-7.

6. Fletcher CDM BJ, Hogendoorn PCW, Mertens F, editors. World Health Organization: World Health Organization classification of tumours of soft tissue and bone. 4th ed. Lyon: IARC Press; 2013. p. 264-74.

7. Gao Y, Moten A, Lin HK. Akt: a new activation mechanism. Cell Res. 2014:24(7):785-6.

8. Giuffrida AY, Burgueno JE, Koniaris LG, Gutierrez JC, Duncan R, Scully SP. Chondrosarcoma in the United States (1973 to 2003): an analysis of 2890 cases from the SEER database. J Bone Joint Surg Am. 2009;91(5):1063-72

9. Ichijo H. From receptors to stress-activated MAP kinases. Oncogene. 1999:18(45):6087-93

10. Jian-Mei Q, Jian-Fei L, Man-Yi Y, Ri-Zheng H, Qing X, Ying-Ming P, Heng-Shan W, Gui-Yang Y. Synthesis and antitumor activities of novel diacerein aaminophosphonates conjugates. Indian Journal of Chemistry 2014; 53B(12):1584-95.

11. Kandel ES, Skeen J, Majewski N, Di Cristofano A, Pandolfi PP, Feliciano CS, et al. Activation of Akt/protein kinase B overcomes a G(2)/m cell cycle checkpoint induced by DNA damage. Mol Cell Biol. 2002;22(22):7831-41.

12. Leeb BF. Clinical efficacy and safety of diacerein in osteoarthritis. european musculoskeletal review. 2010

13. Legendre F, Heuze A, Boukerrouche K, Leclercq S, Boumediene K, Galera P, et al. Rhein, the metabolite of diacerhein, reduces the proliferation of osteoarthritic chondrocytes and synoviocytes without inducing apoptosis. Scand J Rheumatol. 2009:38(2):104-11.

14. Maddika S, Ande SR, Wiechec E, Hansen LL, Wesselborg S, Los M. Aktmediated phosphorylation of CDK2 regulates its dual role in cell cycle progression and apoptosis. J Cell Sci. 2008;121(Pt 7):979-88.

15. Martel-Pelletier J, Mineau F, Jolicoeur FC, Cloutier JM, Pelletier JP. In vitro effects of diacerhein and rhein on interleukin 1 and tumor necrosis factoralpha systems in human osteoarthritic synovium and chondrocytes. J Rheumatol. 1998;25(4):753-62

16. Montenegro MF, Sanchez-del-Campo L, Fernandez-Perez MP, Saez-Ayala M, Cabezas-Herrera J, Rodriguez-Lopez JN. Targeting the epigenetic machinery of cancer cells. Oncogene. 2015;34(2):135-43.

17. Nishida K, Furumatsu T, Takada I, Kawai A, Yoshida A, Kunisada T, et al. Inhibition of human chondrosarcoma cell growth via apoptosis by peroxisome proliferator-activated receptor-gamma. $\mathrm{Br} J$ Cancer. 2002;86(8):1303-9.
18. Pawlik TM, Keyomarsi K. Role of cell cycle in mediating sensitivity to radiotherapy. Int J Radiat Oncol Biol Phys. 2004;59(4):928-42.

19. Pelletier JP, Fernandes JC, Jovanovic DV, Reboul P, Martel-Pelletier J. Chondrocyte death in experimental osteoarthritis is mediated by MEK 1/2 and p38 pathways: role of cyclooxygenase-2 and inducible nitric oxide synthase. J Rheumatol. 2001;28(11):2509-19.

20. Pelletier JP, Mineau F, Boileau C, Martel-Pelletier J. Diacerein reduces the level of cartilage chondrocyte DNA fragmentation and death in experimental dog osteoarthritic cartilage at the same time that it inhibits caspase-3 and inducible nitric oxide synthase. Clin Exp Rheumatol. 2003;21(2):171-7.

21. Sheth DS, Yasko AW, Johnson ME, Ayala AG, Murray JA, Romsdahl MM. Chondrosarcoma of the pelvis. Prognostic factors for 67 patients treated with definitive surgery. Cancer. 1996;78(4):745-50.

22. Shtivelman E, Sussman J, Stokoe D. A role for PI 3-kinase and PKB activity in the G2/M phase of the cell cycle. Curr Biol. 2002;12(11):919-24.

23. Soderstrom M, Ekfors TO, Bohling TO, Teppo LH, Vuorio El, Aro HT. No improvement in the overall survival of 194 patients with chondrosarcoma in Finland in 1971-1990. Acta Orthop Scand. 2003;74(3):344-50.

24. Steinecker-Frohnwieser B, Weigl L, Kullich W, Lohberger B. The disease modifying osteoarthritis drug diacerein is able to antagonize pro inflammatory state of chondrocytes under mild mechanical stimuli. Osteoarthritis Cartilage. 2014;22(7):1044-52

25. Vermeulen K, Berneman ZN, Van Bockstaele DR. Cell cycle and apoptosis Cell Prolif. 2003:36(3):165-75.

26. Vermeulen K, Van Bockstaele DR, Berneman ZN. The cell cycle: a review of regulation, deregulation and therapeutic targets in cancer. Cell Prolif. 2003;36(3):131-49.

27. Wagner EF, Nebreda AR. Signal integration by JNK and p38 MAPK pathways in cancer development. Nat Rev Cancer. 2009;9(8):537-49.

28. Xing JZ, Zhu L, Jackson JA, Gabos S, Sun XJ, Wang XB, et al. Dynamic monitoring of cytotoxicity on microelectronic sensors. Chem Res Toxicol. 2005;18(2):154-61.

29. Xu N, Lao Y, Zhang Y, Gillespie DA. Akt: a double-edged sword in cell proliferation and genome stability. J Oncol. 2012;2012:951724.

30. Zhang W, Liu HT. MAPK signal pathways in the regulation of cell proliferation in mammalian cells. Cell Res. 2002;12(1):9-18.

\section{Submit your next manuscript to BioMed Central and take full advantage of:}

- Convenient online submission

- Thorough peer review

- No space constraints or color figure charges

- Immediate publication on acceptance

- Inclusion in PubMed, CAS, Scopus and Google Scholar

- Research which is freely available for redistribution 